\title{
Ultrasound Assisted Synthesis of Diethyl-2,2'-Thiodiacetate with 2-Bromoethylacetate Under a New Polymer-Supported Phase-Transfer Catalyst in Solid-Liquid Condition
}

\author{
Rajendran $\mathbf{V}^{1 *}$ and Harikumar $\mathrm{K}^{2}$
}

${ }^{1}$ Head of The Department of Chemistry, Pachaiyappa's College for Men, Kanchipuram, TamilNadu, India-631 501

${ }^{2}$ Sri Chandrashekarendra Saraswathi Viswa Mahavidyalaya, Kanchipuram, Enathur, Tamil Nadu, India-631 561

\begin{abstract}
In this work, a new polystyrene-bound single-onium phase-transfer catalyst was synthesized, and their catalytic activities were investigated in the synthesis of diethyl-2,2'-thio diacetate derivatives of thioether. The new insoluble polymer anchored mono-site phase-transfer catalyst showed significant high catalytic activity as compared to soluble single site phase-transfer catalysts. The comparative kinetic investigation reveals that the diethyl-2,2'-thio diacetate of ethyl-2-bromoacetate is faster than sodium sulfide in the presence of the new catalyst. This catalyst can be used several times with consistent catalytic activity. Experimental observations support an interfacial-type mechanism.
\end{abstract}

Keywords: Phase-transfer catalysis; Polymer-supported phasetransfer catalyst; Ultrasound irradiation; Ethyl-2-bromoacetate; Solidliquid reaction; Kinetics.

\section{Introduction}

Currently, phase-transfer catalysis (PTC) is a key green approach [1] for driving reactions involving immiscible reactants [2-6]. However, application of this methodology to organic reactions has encountered two major problems viz.: (i) the recovery and reuse of the catalyst and (ii) the separation and purification of the final product $[7,8]$. To circumvent the predicament of separation of catalyst from the reaction mixture, for the first time Regen [9] reported anchoring the phase-transfer catalysts to a polymer backbone and suggested the name "Triphase Catalysis". Organic reactions catalyzed by triphase catalysts [10-13] have created remarkable attention for its application in synthesis of organic compounds. The vital considerations in the selection of the catalyst are economy of scale and efficiency of the PTC, particularly on the explicit industrial scale preparation of organic compounds. To cater these requirements, multi-site phase-transfer catalysts (MPTC) have been developed and revealed more efficient in activity than conventional single-site phase-transfer catalysts [14-18], and these catalysts are successfully employed for the generation of dihalocyclopropanes [19], which are generally prepared traditionally with lot of predicaments [20]. Synthesis of polymer-supported 'multisite' phase-transfer catalysts (PS-MPTC) of the ammonium type have not been explored much in contrast to the soluble 'multi-site' PTCs. However, the demand and requirement of these triphase catalysts are on the rise due to their popularity.

Thioethers, which have been widely employed as perfume additives [21] and inverse phase-transfer catalysts [22,23] are generally synthesized in a homogeneous reaction [24]. Phase-transfer catalysis (PTC) is well-recognized as a invaluable methodology in organic synthesis in recent years [25-27]. The advantages of the PTC method for synthesizing thioethers are increased reaction rate and selectivity, hydrophilic conditions and low energy requirement. Searching for a more effective condition to enhance the reaction or to elevate the conversion is the primary purpose in phase-transfer catalysis in combined with ultrasonic waves [28-33]. Inventing selective, efficient and eco-friendly methods for applications in complex organic synthetic manipulations constitutes a major chemical research effort. In this regard, several non-conventional methods are emerging that involve reactions in aqueous media $[34,35]$ or those that are accelerated by exposure to microwave [36-38] or ultrasound [39-44] irradiation. These methods are now recognized as viable environmentally benign alternatives. Although, sonication methods have been initially applied to homogeneous reactions in a variety of solvents, this approach has now evolved into a useful technique in heterogeneous reactions. A vast majority of sonochemical applications in the synthesis deal with reactions involving metals [43-52] organic phase insoluble reagents, or their aqueous solutions [53-76]. Our interest was centered on first time evaluating the influence of ultrasound in association with phasetransfer catalyst on the rate of alkyl thioether formation. This work investigates the substitution of alkyl bromides $(\mathrm{RBr})$ to sodium sulfide $\left(\mathrm{Na}_{2} \mathrm{~S}\right)$, including linear and branched alkyl groups and the application of phase-transfer catalysts in combination with ultrasound obviously provides a more efficient synthetic approach for the preparation of thioethers. These PSPTC reactions were carried out in a soiled-liquid two-phase medium. In the absence of a phase-transfer catalyst and ultrasound, less than $5 \%$ conversion was detected even after $4 \mathrm{~h}$ of reaction. In contrast high yields of products were obtained in shorter reaction time using $4 \mathrm{~mol} \%$ (based on the amount of alkyl bromide) of the phase-transfer catalyst, polymer-supported benzyl $\mathrm{N}$-ethyl-N-di-isopropyl ammonium chloride (PSPTC) and ultrasound $40 \mathrm{kHz}(300 \mathrm{~W})$ conditions. Kinetics of the substitution of ethyl-2-bromoacetate to sodium sulfide, including the effect of amount of catalyst, agitation speed, quaternary ammonium salts, amount of sodium hydroxide, organic solvents, temperature and ultrasound frequency on the conversion were investigated in detail.

*Corresponding author: Rajendran V, Head of The Department of Chemistry, Pachaiyappa's College for Men, Kanchipuram, TamilNadu, India, Fax no: +91-4427268824; Email: venugopal.rajendran@ymail.com

Received March 19, 2015; Accepted March 20, 2015; Published March 26, 2015

Citation: Rajendran V, Harikumar K (2015) Ultrasound Assisted Synthesis of Diethyl-2,2'-Thiodiacetate with 2-Bromoethylacetate Under a New PolymerSupported Phase-Transfer Catalyst in Solid-Liquid Condition. Chem Sci J 6: 94 doi:10.4172/2150-3494.100094

Copyright: (c) 2015 Rajendran V, et al. This is an open-access article distributed under the terms of the Creative Commons Attribution License, which permits unrestricted use, distribution, and reproduction in any medium, provided the original author and source are credited. 
With all these antecedents, we decided to synthesize a new monoactive site onium salt with two active sites viz., polymersupported benzyl-N-ethyl-N-di-isopropyl ammonium chloride (PSPTC) by a facile method (Scheme 1).We investigated the catalytic efficiency of the new catalyst by following the comparative kinetics of thioether addition to sodium sulfide and ethyl-2-bromoacetate (EBA) under pseudo-first-order conditions (Scheme 2). Also, to the best of our knowledge, there is no systematic kinetic study of thioetherfication addition to these sodium sulfide involving polymer-supported monosite phase transfer catalysts. Kinetic investigation has been carried out by varying experimental parameters and from the obtained kinetic results, a plausible reaction mechanism has been proposed. Comparative catalytic efficiency of new onium salt and other onium salts (single-active site) were evaluated. (Schemes 3 and 4) shows the images of insoluble polymer-supported benzyl chloride and polymeric insoluble benzylethyldiisopropyl ammonium chloride (PSPTC).

\section{Experimental}

\section{Chemicals}

All the reagents, including, sodium sulfide (Merck), ethyl-2bromoacetate (Merck), polymer-supported benzyl chloride (Aldrich), biphenyl (Aldrich), tetrabutylammonium chloride (TBAC) (CDH), tetrabutylammonium bromide (TBAB) $(\mathrm{CDH})$, benzyltriethylammonium chloride (BTEAC) $(\mathrm{CDH})$, tetraethylammonium chloride (TEAC) $(\mathrm{CDH})$, tetraethylammonium bromide (TEAB) $(\mathrm{CDH})$, potassium hydroxide $(\mathrm{CDH})$, potassium carbonate $(\mathrm{CDH})$, n-hexane $(\mathrm{CDH})$, toluene $(\mathrm{CDH})$, chlorobenzene $(\mathrm{CDH})$, anisole $(\mathrm{CDH})$, diethyl ether $(\mathrm{CDH})$ and other reagents for synthesis were guaranteed grade (GR) chemicals and were used without further purification.

\section{Instrumentation}

${ }^{1} \mathrm{H}$ NMR and ${ }^{13} \mathrm{C}$ spectra were recorded on a Bruker $300 \mathrm{MHz}$ and $75 \mathrm{MHz}$ respective using TMS as an internal standard. Gas chromatography was carried out using a GC-Varian 3700 model. Ultrasonic water bath, Equitron, Media Instrument Manufacturing Company, Chennai, India-600004. The ultrasonic generator was a thermostatic bath equipped with dual frequencies $(28 / 40 \mathrm{kHz})$ and electric power $300 \mathrm{~W}$ with $0.0126 \mathrm{~W} / \mathrm{mL}$ of power density.

\section{Ultrasonic process equipment}

Ultrasonic energy is transmitted to the process vessel through the liquid medium, usually water in the tank. For safety purpose, the sonochemical reactor consisted of two layers stainless steel body. The sonochemical reactor configuration used in the present work is basically an ultrasonic bath. The internal dimension of the ultrasonic cleaner tank is $48 \mathrm{~cm} \times 28 \mathrm{~cm} \times 20 \mathrm{~cm}$ with liquid holding capacity of 5 liters. Two types of frequencies of ultrasound were used in these experiments, which are $28 \mathrm{kHz}$ and $40 \mathrm{kHz}$ with each output as $300 \mathrm{~W}$. Both ultrasounds separately produces through a flat transducer mounted at the bottom of the sonicator. The reactor was a $250 \mathrm{~mL}$ three-necked Pyrex round-bottom flask. This reaction vessel was supported at the centre of the ultrasonic cleaning bath $2 \mathrm{~cm}$ above from the position of the transducer to get the maximum ultrasound energy. All the experimental parameters were done at $40 \mathrm{kHz}$ with output power of $300 \mathrm{~W}$.

\section{Synthesis of a New PSPTC}

Preparation of a new polymer-supported benzyl N-ethyl-Ndi-isopropyl ammonium chloride (PSPTC)

In the polymer-supported benzyl chloride $(2 \mathrm{~g})$ was swelled in acetonitrile $(150 \mathrm{~mL})$ for about $24 \mathrm{~h}$ and transferred into a $500 \mathrm{~mL}$ three- necked round bottomed flask with excess diisopropylethylamine (20 $\mathrm{mL}$ ). The reaction mixture was stirred continuously using a mechanical stirrer equipped with a poly (tetrafluoroethylene) (PTFE) half-moon blade agitating at $600 \mathrm{rpm}$ under a nitrogen atmosphere. The reaction was carried out at reflux condition for $50 \mathrm{~h}$. The solvent was then completely removed under vacuo and the onium salt viz., polymer-supported benzyl N-ethyl$\mathrm{N}$-di-isopropyl ammonium chloride (PSPTC) was washed with diethyl ether, methanol and acetone (Scheme 2) was stored in a $\mathrm{CaCl}_{2}$ desiccator. The extent of quaternization, the amount of chloride ion present in the PSPTC was quantitatively estimated by Volhard's method and found to be 1.1 mequiv $^{-1}$.

FT-IR (KBr), $\mathrm{cm}^{-1}:$ 1152(C-N $\left.{ }^{+}\right), 1443(\mathrm{C}-\mathrm{C}), 1605$ (aromatic C=C), 2931(alkyl stretching).

\section{Synthesis of Diethyl-2,2'-Thiodiacetate under Mechanical Stirring}

Synthesis of diethyl-2,2'-thiodiacetate under mechanical stirring. To the mixture of $\mathrm{Na}_{2} \mathrm{~S}(6 \mathrm{~g}, 77 \mathrm{mmol})$ in water $(10 \mathrm{~mL})$ and the

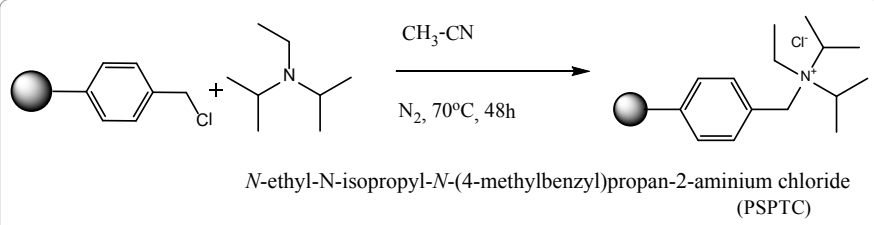

Scheme 1: Synthesis of polymeric benzylethyldiisopropylammonium chloride

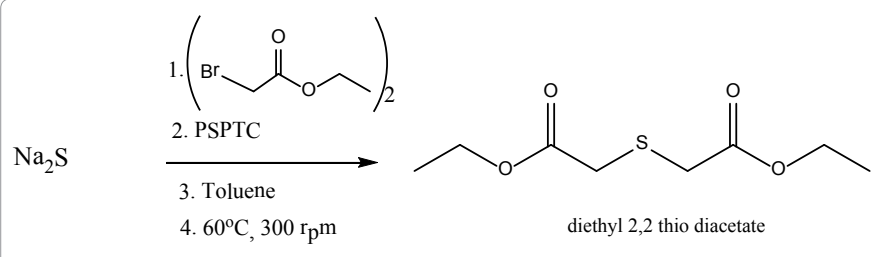

Scheme 2: Preparation of diethyl-2,2'-thidiacetate.

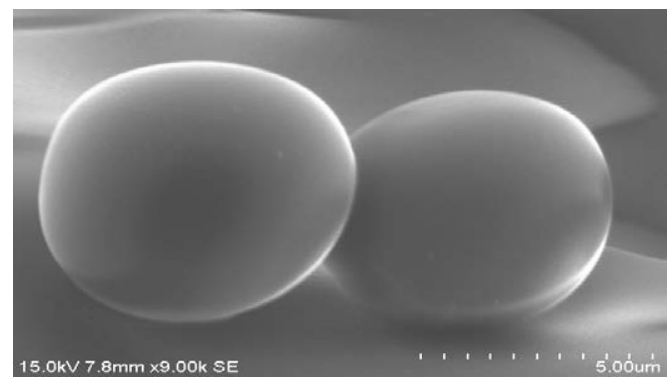

Scheme 3: SEM image of polymer-supported benzyl chloride.

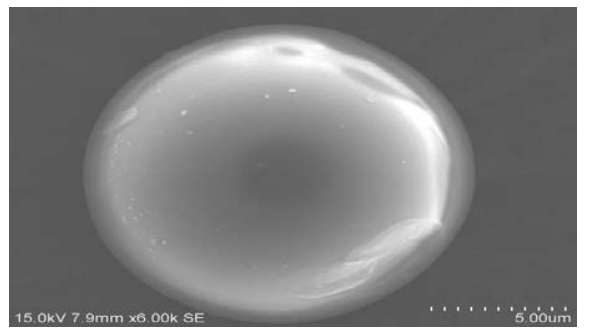

Scheme 4: SEM image of polymer supported phase-transfer catalyst (PSPTC). 
Citation: Rajendran V, Harikumar K (2015) Ultrasound Assisted Synthesis of Diethyl-2,2'-Thiodiacetate with 2-Bromoethylacetate Under a New Polymer-Supported Phase-Transfer Catalyst in Solid-Liquid Condition. Chem Sci J 6: 94. doi:10.4172/2150-3494.100094

newly synthesized PSPTC (1.0 g), was added under overhead stirring to generate the sulphur anion. Then ethyl-2-bromo acetate $(1.0 \mathrm{~g}$, $6 \mathrm{mmol})$ in chlorobenzene $(40 \mathrm{~mL})$ was added slowly. The reaction mixture was heated at $60^{\circ} \mathrm{C}$ for $4 \mathrm{~h}$ with vigorous stirring. The crude product was isolated by simple extraction with diethyl ether $(3 \times 25$ $\mathrm{mL}$ ). The organic layer was collected and the solvent was evaporated under reduced pressure. The crude product was chromatographic $\left(\mathrm{SiO}_{2}\right)$ employing hexane:ethyl acetate $(9: 1)$ as an eluent to obtain a pure monoderivative. The identity of the product was confirmed by ${ }^{1} \mathrm{H}$ NMR and ${ }^{13} \mathrm{C}$ NMR spectra of the product. m.pt. 306-308 -C; Yield: $88 \%$; $1 \mathrm{H} \mathrm{NMR}\left(400 \mathrm{MHz}, \mathrm{CDCl}_{3}\right)$ : d . 0.96-0.98 (t, 3H, $\left.\mathrm{CH}_{3}\right)$, 5.34-1.33-1.45 (m, 2H, CH $), 1.71-1.86\left(\mathrm{~m}, 2 \mathrm{H}, \mathrm{CH}_{2}\right), 3.90-4.01(\mathrm{t}$, $\left.3 \mathrm{H}, \mathrm{CH}_{3}\right), 7.13,8.18(\mathrm{~m}, 4 \mathrm{H}, \mathrm{Ar}-\mathrm{CH}){ }^{13} \mathrm{C} \mathrm{NMR}\left(100 \mathrm{MHz}, \mathrm{CDCl}_{3}\right)$ : d. $14.12\left(\mathrm{CH}_{3}\right), 19.16\left(\mathrm{CH}_{3}\right), 32.01\left(\mathrm{CH}_{2}\right), 68.67\left(\mathrm{CH}_{2}\right), 115.31,121.72$, $140.05,163.64(\mathrm{Ar}-\mathrm{CH})$.

\section{Reaction Mechanism and Kinetic Model}

The reaction was conducted in a $250 \mathrm{~mL}$ three-necked Pyrex round-bottom flask which permits agitating the solution, inserting the water condenser to recover organic reactant and taking samples and feeding the reactants. This reaction vessel was supported at the centre of the sonicator. Known quantities of chlorobenzene (30 $\mathrm{mL}$, solvent), sodium sulfide powder $(6 \mathrm{~g}$ in $10 \mathrm{~mL}$ water $)$ and $0.2 \mathrm{~g}$ biphenyl (IS-internal standard) were introduced into the reactor. Then, $1.0 \mathrm{~g}$ of ethyl-2-bromo acetate $(6 \mathrm{mmol})$ and $1.0 \mathrm{~g}$ of the newly synthesized PSPTC were introduced to the reactor to start the reaction. The reaction mixture was stirred at $300 \mathrm{rpm}$. The phase separation was almost immediate on arresting the stirring process. Samples were collected from the organic layer of the mixture (by stopping the stirring for 20-30 seconds each time) at regular time intervals. A pinch of anhydrous $\mathrm{CaCl}_{2}$ was placed in the sample vials to absorb any moisture present in the organic layer. Each run consisted of six samples taken over the period ranging from 5 to 30 minutes. The kinetics was followed by estimating the amount of ethyl-2-bromoacetate that disappeared and measured by a gas Chromatography (GC-Varian 3700 model). The analyzing conditions were as follows; Column, $30 \mathrm{~m} \times 0.525 \mathrm{~mm}$ i.d. capillary column containing $100 \%$ poly(dimethyl siloxanen); injection temperature, $250^{\circ} \mathrm{C}$; FID detector $\left(300^{\circ} \mathrm{C}\right)$. Yields were determined from standard curve using biphenyl as an internal standard.

\section{Definition}

The conversion $(\mathrm{X})$ of ethyl-2-bromo acetate (EBA) is defined as follows:

$$
\mathrm{X}=1-\left\{[\mathrm{EBA}]_{0} /[\mathrm{EBA}]_{\circ, \mathrm{o}}\right\}
$$

Where $[\mathrm{EBA}]_{0}$ and $[\mathrm{EBA}]_{\mathrm{o}, \mathrm{t}}$ represent the concentration of ethyl-2bromo acetate in the organic phase at a given time $(t) t=0$ and $t>0$, respectively.

\section{Rate expression}

The rate expression for this reaction may be expressed as;

$$
-\mathrm{r}_{\mathrm{EBA}}=\mathrm{k}_{\text {app }}[\mathrm{EBA}]_{\mathrm{o} . \mathrm{t}}
$$

Where $[\mathrm{EBA}]_{\mathrm{o}, \mathrm{t}}$ is concentration of ethyl-2-bromo acetate in the organic phase and $\mathrm{k}_{\text {app }}$ is the apparent reaction rate constant. This reaction is carried out in a batch reactor, so the diminution rate of EBA with time $(\mathrm{t})$ can be expressed as:

$$
-\mathrm{d}[\mathrm{EBA}]_{0} / \mathrm{dt}=-\mathrm{r}_{\mathrm{EBA}}=\mathrm{k}_{\mathrm{app}}[\mathrm{EBA}]_{\mathrm{o}, \mathrm{t}}
$$

\section{On integrating the Eq. (3) yields:}

$$
-\ln (1-X)=k_{\text {app }} \times t
$$

Using Eq. (4), we can get the $\mathrm{k}_{\text {app }}$ value experimentally by plotting $-\ln (1-\mathrm{X})$ against time, $(\mathrm{t})$.

\section{Results and Discussion}

\section{Effects of ultrasound and mechanical stirring on the reaction}

To ascertain the influence of agitation speed on the rate of thioeitherfication of sodium sulfide, the speed of agitation was varied in the range of 0-500 rpm along with ultrasound irradiation $(40 \mathrm{kHz}$, $300 \mathrm{~W}$ ) using polymer-supported benzyl N-ethyl-N-di-isopropyl ammonium chloride (PSPTC) In principle, the homogeneous reaction is independent of the agitation speed. As shown in (Figure 1), that the rate of the reaction increases linearly as the agitation speeds increases from 0 to $300 \mathrm{rpm}$. Macroscopically, this result indicates that the reaction is carried out in a solid-liquid phase. In fact, the reaction proceeds by accompanying with the dissolving $\mathrm{Na}_{2} \mathrm{~S}$ in chlorobenzene. The dissolving rate of $\mathrm{Na}_{2} \mathrm{~S}$ in chlorobenzene is highly influenced by the agitation speed. In general, a high concentration of $\mathrm{Na}_{2} \mathrm{~S}$ dissolving in organic solvent is obtained at a high agitation speed. Therefore, the conversion of ethyl-2-bromo acetate was increased with the increase in the agitation speed up to $300 \mathrm{rpm}$. For agitation speeds higher than $300 \mathrm{rpm}$, the conversion is influenced almost not at all by the agitation speed. The purpose of stirring is to provide a well mixing to dissolve $\mathrm{Na}_{2} \mathrm{~S}$ in the chlorobenzene in the ethyl-2-bromo acetate presence of PSPTC to form $\mathrm{Q}_{2} \mathrm{~S}$. Then, the dissolved $\mathrm{Q}_{2} \mathrm{~S}$ reacted with to produce ethyl-2-bromoacetate. Therefore, the agitation speed was set at 300 $\mathrm{rpm}$ for studying the reaction phenomena from which the resistance of mass transfer stays at a constant value [27-35]. The $\mathrm{k}_{\text {app }}$ values indicate that the mechanical effects brought up by the use of low frequency ultrasounds are responsible of the enhancement of the kinetics by harsh mixing, enhancement of mass transfer and in solid-liquid systems, high erosion of the solid particles occurs and consequently the surface area is increased. So on, further when the same reaction was carried out in conventional method, the observed $\mathrm{k}_{\text {app }}$ value $\left(\mathrm{k}_{\mathrm{app}}=6.2 \times 10^{-3}, \mathrm{~min}^{-1}\right)$ almost four fold lesser than in the presence of ultrasonication $(40 \mathrm{kHz}$, $300 \mathrm{~W}, 300 \mathrm{rpm}: \mathrm{k}_{\mathrm{app}}=24.63 \times 10^{-3}, \mathrm{~min}^{-1}$ ).

\section{Effect of the amount of newly prepared PSPTC}

The experiments were conducted by varying the amount of the newly synthesized polymer-supported benzyl-N-ethyl$\mathrm{N}$-diisopropylammonium chloride (PSPTC) by keeping other experimental parameters are kept constant. The influence of the amount of PSPTC has been studied by varying the amount of PSPTC from $0.5 \mathrm{~g}$ to $2.5 \mathrm{~g}$ with respect to ethyl-2-bromo acetate (EBA) under ultrasound irradiation $(40 \mathrm{kHz}, 300 \mathrm{~W})$. As shown in (Table 1) and (Figure 2), the rate of conversion is increased with increasing in the amount of PSPTC along with ultrasound irradiation $(40 \mathrm{kHz}, 300 \mathrm{~W})$. The conversion about $75 \%$ in the higher concentration of polymer-supported monosite phase-transfer catalyst in 30 minutes of the reaction. The increase in the $\mathrm{k}_{\text {app }}$ value is attributed to the synergic effect of ultrasound might be enlarged [36]. The small amount of water can efficiently promote the solubilization of the solid reactant and thus enhance the formation of catalytic intermediate $\left(\mathrm{Q}_{2} \mathrm{~S}\right)$. All the further experiments were done at $1.0 \mathrm{~g}$ of catalyst amount.

\section{Effect of the amount of ethyl-2-bromoacetate}

To investigate the influence of ethyl-2-bromoacetate (EBA) on the kinetics of synthesis of ethyl-2-bromoacetate under ultrasonic 


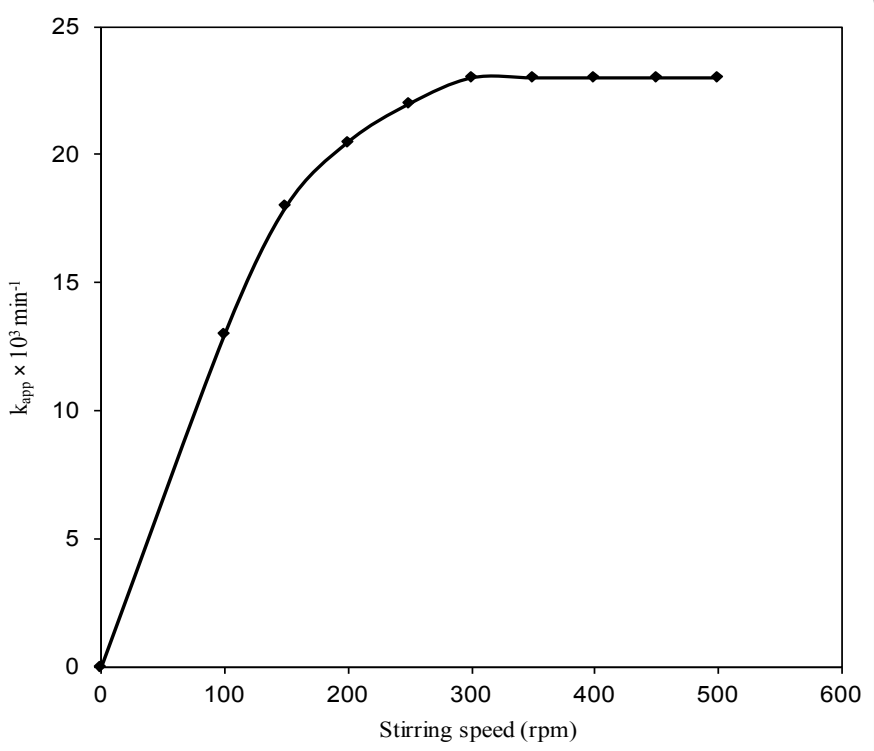

Figure 1: Effect of ultrasound and mechanical stirring speeds on the synthesis of diethyl-2,2'-thiodiacetate: $\mathrm{Na}_{2} \mathrm{~S}(9.25 \mathrm{mmol})$, ethylbromoacetate $(6.35$ $\mathrm{mmol}$ ), $1.0 \mathrm{~g}$ PSPTC, $0.2 \mathrm{~g}$ biphenyl (internal standard), chlorobenzene $30 \mathrm{~mL}$, $60^{\circ} \mathrm{C}, 40 \mathrm{kHz}, 300 \mathrm{~W}$.

\begin{tabular}{|c|c|}
\hline \multicolumn{2}{|c|}{ Effect of the amount of PSPTC } \\
\hline PSPTC (gm) & $\begin{array}{c}\mathbf{k}_{\text {app }} \times \mathbf{1 0}_{\mathbf{3}}, \mathbf{~ m i n}^{-1} \\
(\mathbf{4 0} \mathbf{~ H z}, \mathbf{3 0 0 W})\end{array}$ \\
\hline 0.5 & 12.24 \\
1.0 & 24.63 \\
1.5 & 29.02 \\
2.0 & 41.68 \\
2.5 & 47.82 \\
\hline
\end{tabular}

Table 1: Effect of the amount of PSPTC on the synthesis of diethyl-2,2'thiodiacetate: $\mathrm{Na}_{2} \mathrm{~S}(9.25 \mathrm{mmol})$, ethylbromoacetate $(6.35 \mathrm{mmol}), 0.2 \mathrm{~g}$ biphenyl (internal Standard), chlorobenzene $30 \mathrm{~mL}, 60^{\circ} \mathrm{C}, 300 \mathrm{rpm}, 40 \mathrm{kHz}, 300 \mathrm{~W}$.

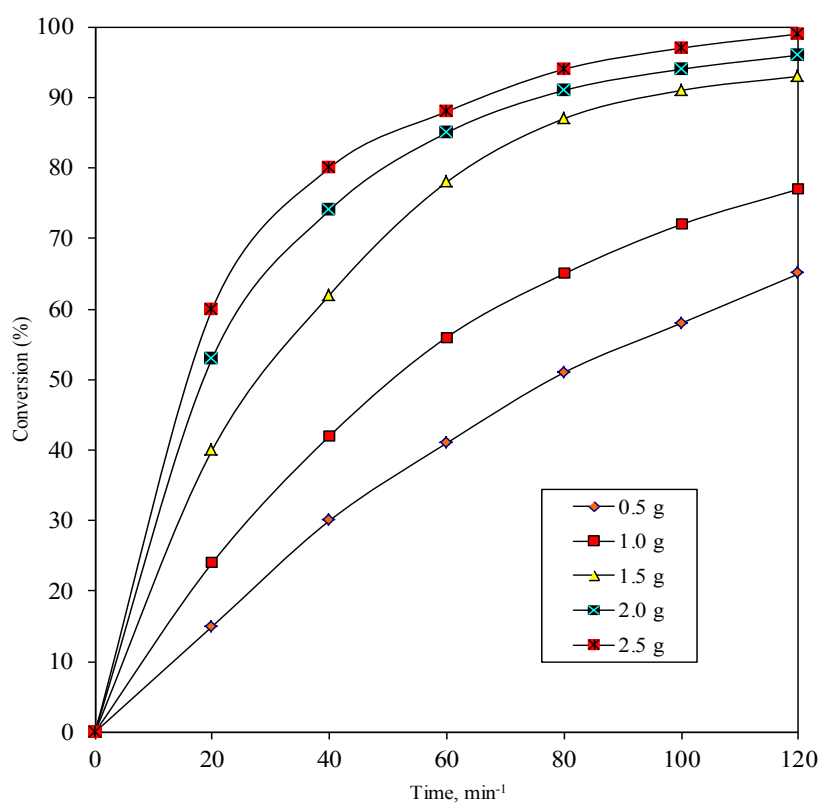

Figure 2: Effect of the amount of PSPTC on the synthesis of diethyl-2,2'thiodiacetate: $\mathrm{Na}_{2} \mathrm{~S}(9.25 \mathrm{mmol})$, ethylbromoacetate $(6.35 \mathrm{mmol}), 0.2 \mathrm{~g}$ biphenyl (internal standard), chlorobenzene $30 \mathrm{~mL}, 60^{\circ} \mathrm{C}, 300 \mathrm{rpm}, 40 \mathrm{kHz}$ $300 \mathrm{~W}$. irradiation condition $(40 \mathrm{kHz}, 300 \mathrm{~W})$, the amount of EBA was varied from $0.25 \mathrm{~g}$ to $2.0 \mathrm{~g}$. The results are shown in (Table 2 ). The data clearly indicates that the $\mathrm{k}_{\text {app }}$ value increases with increasing the amount of EBA. When the ethyl-2-bromoacetateconcentrations increased, the probability of finding the substrate with active-site of the catalyst and ultrasound enhanced the rate of the reaction [36,37]. It may be due to reduces the surface area between the solid and organic phases, and hence more reactants collide to each other simultaneously we get higher $\mathrm{k}_{\mathrm{app}}$ value.

\section{Effect of temperature}

The effect of temperature on the reaction between sodium sulfide and ethyl-2-bromoacetate was studied under otherwise similar conditions. The temperature was varied from 40 to $80^{\circ} \mathrm{C}$ (Figure 3 ). The kinetic profile of the reaction is obtained by plotting $-\ln (1-\mathrm{X})$ versus time. It is obvious that the reactivity is increased with an increase in the temperature along with ultrasonic effect [38]. The reason is that the number of reactant molecules which possess higher activation energy at a higher temperature and thus the ultrasonic wave easily passes through the reactor $[39,40]$. The other point is that the collision of the reactants at higher temperature is also increased. Hence, the apparent rate constant is increased at higher temperature. Arrhenius plots were made in (Figure 4) of $-\operatorname{lnk}_{\text {app }}$ against $1 / \mathrm{T}$ to get activation energy of $53.32 \mathrm{~kJ} \mathrm{~mol}^{-1}$. From the literature survey, the dehydrobromination of (2-bromoethyl) benzene catalyzed by tetraoctylammonium bromide (TOAB), an extraction mechanism was proposed [41] due to lower $\mathrm{E}_{\mathrm{a}}$ value $\left(<43 \mathrm{~kJ} \mathrm{~mol}^{-1}\right)$. In general, higher activation energy (more than $43 \mathrm{~kJ} \mathrm{~mol}^{-1}$ ) suggests an interfacial mechanism [37,42]. The activation energy for the heterogeneous ethylation of phenylactonitrile was reported to be $63.64 \mathrm{~kJ} \mathrm{~mol}^{-1}$ and for this an interfacial mechanism was proposed $[43,44]$. Further they concluded that the deprotonation of the substrate takes place at the inter-phase and consequently the organic anion is extracted and reacts in the bulk organic phase. The rate-determining step in the process is the anion exchange at the interphase. In our study, the observed $\mathrm{E}_{\mathrm{a}}$ value is $53.32 \mathrm{~kJ} \mathrm{~mol}^{-1}(64.66 \mathrm{~kJ}$ $\mathrm{mol}^{-1}$ under silent condition). Hence, we proposed an interfacial mechanism for our present study $[37,46]$.

\section{Effect of ultrasonic frequency}

Ultrasonic irradiation is defines as acoustic waves with frequencies in the $20 \mathrm{kHz}-100 \mathrm{MHz}$ range [47]. They create cavities generating locally high temperature and pressures [48-51] or strong electric fields [49, 51-53]. Ultrasound is known to accelerate diverse types of organic reactions and it is established generous reactions, which are otherwise slow due to poor mass transfer are accelerated by sonication due to cavitations [50]. It has been reported that a combination of PTC and ultrasound is often better than either of the two techniques alone [51]. In such transfer of species across the interface and ultrasound merely facilitates this transfer, possibly by increasing the interfacial area across which this transfer occurs.

To ascertain the influence of various ultrasonic frequencies on the rate of the reaction with same output power of $300 \mathrm{~W}$, the ultrasonic frequency was varied between 28 and $40 \mathrm{kHz}$ under otherwise similar conditions using PSPTC as the catalyst and also we followed the reaction under silent condition $(0 \mathrm{kHz})$. The kinetic profile of the reaction is obtained by plotting $-\ln (1-\mathrm{X})$ against time. In our experimental condition at 30 minutes, without ultrasonic irradiation (silent condition) the $\mathrm{k}_{\text {app }}$ values is $6.20 \times 10^{-3}, \mathrm{~min}^{-1}$ but in the presence of ultrasonic condition the $\mathrm{k}_{\text {app }}$ values are $17.51 \times 10^{-3} \mathrm{~min}^{-1}$ and $24.63 \times$ 


\begin{tabular}{|c|c|}
\hline \multicolumn{2}{|c|}{ Effect of amount of ethyl-2-bromoacetate } \\
\hline $\begin{array}{l}\text { Ethyl-2-bromoacetate } \\
\text { (EBA), g }\end{array}$ & $\begin{array}{l}k_{\text {app }} \times 10^{3} \mathrm{~min}^{-1} \\
(40 \mathrm{kHz}, 300 \mathrm{~W})\end{array}$ \\
\hline 0.25 & 13.23 \\
\hline 0.5 & 19.52 \\
\hline 1.0 & 24.63 \\
\hline 1.5 & 28.30 \\
\hline 2.0 & 31.78 \\
\hline
\end{tabular}

Table 2: Effect of the amount of ethyl-2-bromoacetate (EBA) on the rate of synthesis of diethyl-2,2'-thiodiacetate : $\mathrm{Na}_{2} \mathrm{~S}(9.25 \mathrm{mmol})$, ethylbromoacetate $(6.35$ $\mathrm{mmol}$ ), $0.2 \mathrm{~g}$ biphenyl (internal Standard), chlorobenzene $30 \mathrm{~mL}, 60^{\circ} \mathrm{C}$, PSPTC 1 g, $300 \mathrm{rpm}, 40 \mathrm{kHz}, 300 \mathrm{~W}$.

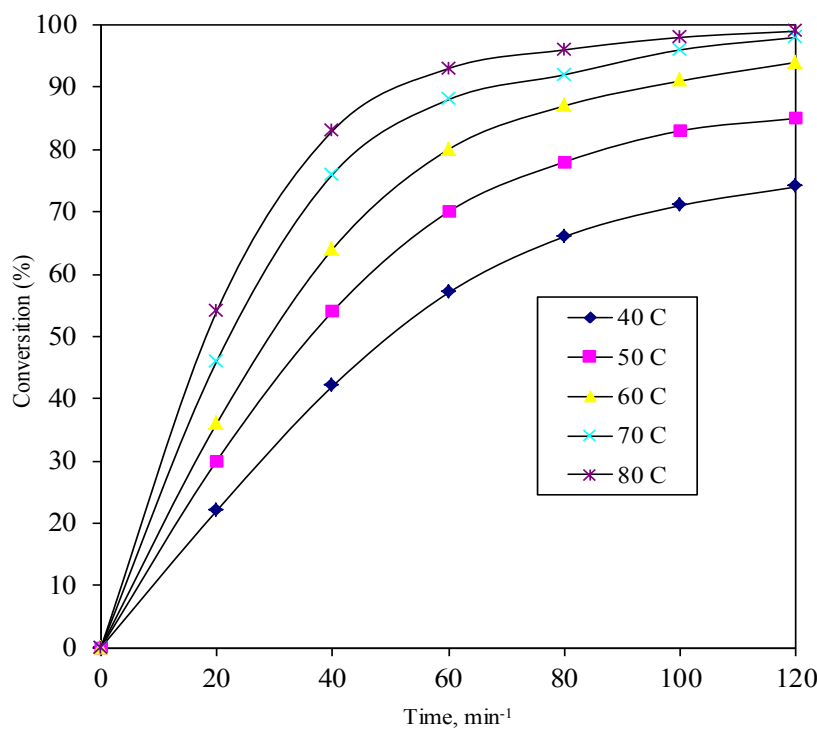

Figure 3: Effect of temperature on the synthesis of diethyl-2,2'-thiodiacetate: Na2S $(9.25 \mathrm{mmol})$, ethylbromoacetate $(6.35 \mathrm{mmol}), 0.2 \mathrm{~g}$ biphenyl (internal standard), chlorobenzene $30 \mathrm{~mL}, 60^{\circ} \mathrm{C}$, PSPTC $1 \mathrm{~g}, 300 \mathrm{rpm}, 40 \mathrm{kHz}, 300 \mathrm{~W}$.

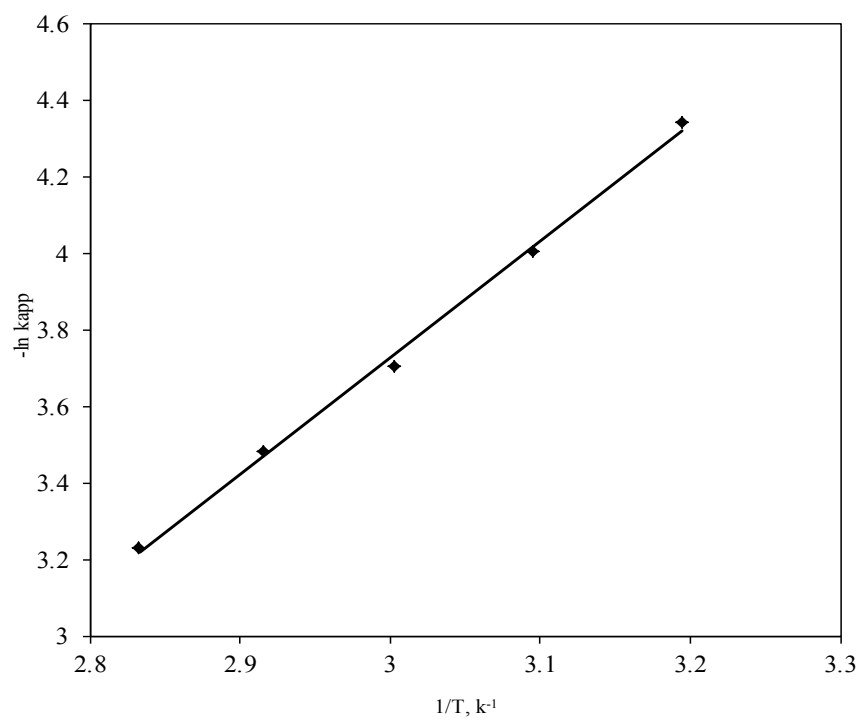

Figure 4: Arrhenius plot on the synthesis of diethyl-2,2'-thiodiacetate: $\mathrm{Na}_{2} \mathrm{~S}(9.25 \mathrm{mmol})$, ethylbromoacetate $(6.35 \mathrm{mmol}), 0.2 \mathrm{~g}$ biphenyl (internal standard), chlorobenzene $30 \mathrm{~mL}, 60^{\circ} \mathrm{C}$, PSPTC $1 \mathrm{~g}, 300 \mathrm{rpm}, 40 \mathrm{kHz}, 300 \mathrm{~W}$.

$10^{-3} \mathrm{~min}^{-1}$ for $28 \mathrm{kHz}(300 \mathrm{~W})$ and $40 \mathrm{kHz}(300 \mathrm{~W})$, respectively (Table 3). Hence, the overall $k_{\text {app }}$ was increased by increasing the ultrasonic frequency in the order of $0 \mathrm{kHz}$ (silent condition) $<28 \mathrm{kHz}(300 \mathrm{~W})<40$ $\mathrm{kHz}(300 \mathrm{~W})$ for our system (Table 2). Similar trend was observed by Wang et al. [54,55].

\section{Effect of organic solvents}

The influence of various organic solvents on the rate of thioeitherfication of sodium sulfide was followed under otherwise standard reaction conditions. Five organic solvents employed in this study are toluene, anisole, cyclohexane, chlorobenzene, and n-hexane. From the plot of $-\ln (1-\mathrm{X})$ against time, the $\mathrm{k}_{\text {app }}$ values are obtained. From the (Table 4), chlorobenzene possesses a higher $\mathrm{k}_{\text {app }}$ value among the five organic solvents, due to its higher dielectric constant. In another view the ultrasonic irradiation can enhance the rate in the presence of more polar solvents due to passing higher ultrasonic waves to the reactor and makes fruitful collision between the reactants, and hence we get higher $\mathrm{k}_{\mathrm{app}}$ value for chlorobenzene solvent of this system and also this statement is not always true [56-62].

\section{Effect of volume of chlorobenzene}

In a homogeneous reaction, the reaction follows the intrinsic kinetic law. The conversion or the reaction rate is directly proportional to the concentration of the reactants in $30 \mathrm{~min}$ of reaction. A dilute concentration of the reactant is obtained using a large amount of organic solvent. The conversion of ethyl-2-bromoacetate is increased with the decrease in the volume of chlorobenzene (Table 5). (Figure 5) shows the dependence of the \% conversion on the volume of chlorobenzene. The $\mathrm{k}_{\text {app }}$ value is inversely proportional to the volume of chlorobenzene, as expected.

\section{Effect of different phase-transfer catalysts}

Comprehensive comparativekineticstudiesforthethioeitherfication of sodium sulfide by ethyl-2-bromoacetate (EBA) were carried out using $5 \mathrm{~mol} \%$ of various onium salts viz., polymer-supported benzyl-N-ethyl-N-diisopropylammonium chloride (PSPTC), tetraethylammonium chloride (TEAC), tetraethylammonium bromide (TEAB), tetrabutylammoniun chloride (TBAC), tetrabutylammonium bromide (TBAB), benzyltriethylammonium chloride (BTEAC), and benzyltriethylammonium bromide (BTEAB). The pseudo-first order rate constant are evaluated for all the catalyst from the plot of $-\ln (1-\mathrm{X})$ versus time and are presented in (Table 6) with ultrasonic condition. The order of the relativities of these quaternary ammonium salts are in

\begin{tabular}{|c|c|}
\hline \multicolumn{2}{|c|}{ Effect of ultrasonic frequency } \\
\hline Ultrasonic frequency $(\mathbf{k H z})$ & $\mathbf{k}_{\text {app }} \mathbf{\times} \mathbf{1 0}^{\mathbf{3}}, \mathbf{m i n}^{-1}$ \\
\hline 0 (Silent) & 6.20 \\
28 & 17.51 \\
40 & 24.63 \\
\hline
\end{tabular}

Table 3: Influence of the ultrasonic frequencies on the rate of synthesis of diethyl2,2'-thiodiacetate: $\mathrm{Na}_{2} \mathrm{~S}(9.25 \mathrm{mmol})$, ethylbromoacetate $(6.35 \mathrm{mmol}), 0.2 \mathrm{~g}$ biphenyl (internal Standard), chlorobenzene $30 \mathrm{~mL}, 60^{\circ} \mathrm{C}$, PSPTC $1 \mathrm{~g}, 300 \mathrm{rpm}$.

\begin{tabular}{|c|c|c|}
\hline \multicolumn{3}{|c|}{ Effect of organic solvents } \\
\hline Solvents & $\begin{array}{l}\text { dielectric constant } \\
(\varepsilon)\end{array}$ & $\begin{array}{l}k_{\mathrm{app}} \times 10^{3}, \mathrm{~min}^{-1} \\
(40 \mathrm{kHz}, 300 \mathrm{~W})\end{array}$ \\
\hline Chlorobenzene & 5.6 & 24.63 \\
\hline Anisole & 4.3 & 21.76 \\
\hline Toluene & 2.4 & 15.24 \\
\hline Hexane & 2.2 & 11.52 \\
\hline Cyclohexane & 2.0 & 9.68 \\
\hline
\end{tabular}

Table 4: Influence of organic solvents on the rate of the synthesis of diethyl-2,2' thiodiacetate: $\mathrm{Na}_{2} \mathrm{~S}(9.25 \mathrm{mmol})$, ethylbromoacetate $(6.35 \mathrm{mmol}), 0.2 \mathrm{~g}$ biphenyl (internal Standard), PSPTC 1g, $60^{\circ} \mathrm{C}$, PSPTC $1 \mathrm{~g}, 300 \mathrm{rpm}, 40 \mathrm{kHz}, 300 \mathrm{~W}$. 


\begin{tabular}{|c|c|}
\hline \multicolumn{2}{|c|}{ Effect of different phase-transfer catalysts } \\
\hline $\begin{array}{c}\text { PTC } \\
(\mathbf{5} \text { mol\% with respect ethyl-2- } \\
\text { bromoacetate) }\end{array}$ & $\begin{array}{c}\mathbf{k}_{\text {app }} \mathbf{\times} \mathbf{1 0}^{\mathbf{3}}, \mathbf{m i n}^{-1} \\
\mathbf{( 4 0} \mathbf{~ k H z}, \mathbf{3 0 0 W})\end{array}$ \\
\hline TBAB & 16.86 \\
TBAC & 16.31 \\
BTEAC & 15.58 \\
TEAB & 14.33 \\
TEAC & 13.56 \\
\hline
\end{tabular}

Table 5: Effect of various PTC's ( $5 \mathrm{~mol} \%$ based on ethylbromoacetate) on the rate of synthesis of diethyl-2,2'-thiodiacetate: $\mathrm{Na}_{2} \mathrm{~S}(9.25 \mathrm{mmol})$, ethylbromoacetate $(6.35 \mathrm{mmol}), 0.2 \mathrm{~g}$ biphenyl (internal Standard), chlorobenzene $30 \mathrm{~mL}, 60^{\circ} \mathrm{C}$, PSPTC $1 \mathrm{~g}, 300 \mathrm{rpm}, 40 \mathrm{kHz}, 300 \mathrm{~W}$.

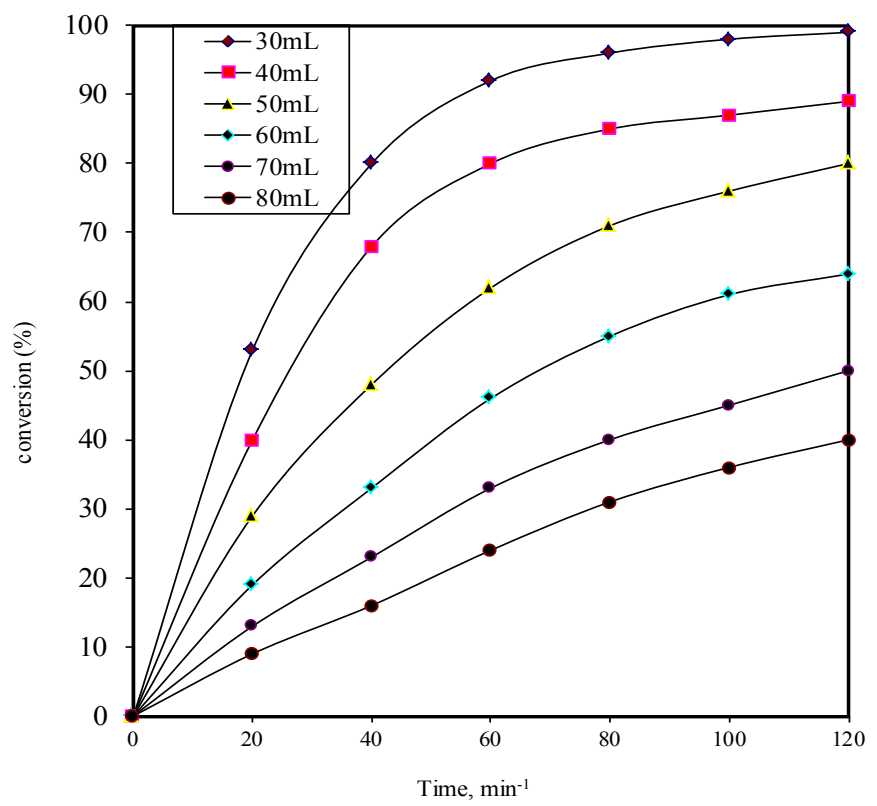

Figure 5: Effect of the volume of solvent chlorobenzene on the synthesis of diethyl-2,2'-thiodiacetate: $\mathrm{Na}_{2} \mathrm{~S}(9.25 \mathrm{mmol})$, ethylbromoacetate $(6.35 \mathrm{mmol})$, $0.2 \mathrm{~g}$ biphenyl (internal standard), $60^{\circ} \mathrm{C}$, PSPTC $1 \mathrm{~g}, 300 \mathrm{rpm}, 40 \mathrm{kHz}, 300 \mathrm{~W}$.

\begin{tabular}{|c|c|}
\hline Volume of chlorobenzene $(\mathbf{m L})$ & $\begin{array}{c}\mathbf{k}_{\text {app }} \mathbf{1 0}^{\mathbf{3}}, \mathbf{~ m i n}^{-\mathbf{1}} \\
(\mathbf{4 0} \mathbf{~ k H z}, \mathbf{3 0 0 W} \mathbf{)})\end{array}$ \\
\hline 30 & 24.63 \\
40 & 19.36 \\
50 & 15.02 \\
60 & 12.22 \\
80 & 10.56 \\
\hline 0.76 \\
\hline
\end{tabular}

Table 6: Effect of the volume of chlorobenzene on the rate of synthesis of diethyl2,2'-thiodiacetate: $\mathrm{Na}_{2} \mathrm{~S}(9.25 \mathrm{mmol})$, ethylbromoacetate $(6.35 \mathrm{mmol}), \quad 0.2 \mathrm{~g}$ biphenyl (internal Standard), $60^{\circ} \mathrm{C}$, PSPTC $1 \mathrm{~g}, 300 \mathrm{rpm}, 40 \mathrm{kHz}, 300 \mathrm{~W}$.

the order $\mathrm{TBAB}>\mathrm{TBAC}>\mathrm{BTEAC}>\mathrm{TEAB}>\mathrm{TEAC}$. It is thus concluded that the order of the reactivity is TEA cation $>$ BTEA cation $>$ TBA cation, which is consistent with the result [42] obtained by Wang and Rajendran combined with ultrasonic dichlorocarbene addition to 1,7-octadiene under PTC condition. The result indicates that the $\mathrm{k}_{\text {app }}$ value depends on organophilisity of the onium salts along with ultrasonic irradiation condition (Table 5) [36, 63-68].

\section{Effect of water}

The critical effect of traces of water on solid-liquid phase transfer reactions has been studied in detail by several groups [4,69-77]. In solid-liquid system, the addition of small amount of water can be useful in forming the catalytic intermediate for conducting intrinsic reactions. The effect of water on this SLPTC was explored using under $300 \mathrm{rpm}$ and ultrasonic irradiation $(40 \mathrm{kHz}, 300 \mathrm{~W})$. (Figure 6) is the plot of conversion versus volume of water $(\mathrm{mL})$ for different amounts of water added, showing that pseudo-first-order kinetic equation can be successfully used to describe the ultrasound assisted-SLPTC system. Without adding water, only $47 \%$ of product yield was obtained in 60 minute of reaction; but merely with $1 \mathrm{~mL}$ of water in the system, the product yield largely increased to $85.3 \%$. Continuing to increase the quantity of water, the reaction rate was increased for further $1 \mathrm{~mL}$ and then gradually reduced. When the amount of water was added to $30 \mathrm{~mL}$, the solid-liquid system became a liquid-liquid type, and the product yield greatly decreased to $30 \%$, much lower than that in SLPTC. The increase of reaction rate with small amount of water was mainly due to water solubilizing a small part of solid reactant to increase the production of $\left(\mathrm{Q}^{+}\right)_{2} \mathrm{~S}^{2-}$ in the inter-phase, thus enhancing the intrinsic reaction rate. When more water was added, the effective concentration of $\left(\mathrm{Q}^{+}\right)_{2} \mathrm{~S}^{2-}$ in the inter-phase would be decreased and the reaction rate was reduced. In the absence of water, the reaction rate of solid reactant and PSPTC in the organic phase was slow, resulting in small product yield $49 \%$ after 30 min of reaction. With only $1 \mathrm{~mL}$ of water, the formation of $\left(\mathrm{Q}^{+}\right)_{2} \mathrm{~S}^{2-}$ greatly increased and concentrated in the inter-phase and leads to the bulk organic phase where the intrinsic reaction take place.

\section{Discussion of the Reaction between Sodium Sulfide and Ethyl-2-Bromoacetate}

Known quantities of polymer-supported mono-site phase transfer catalyst (PSPTC) viz., polymer-supported benzyl-N-ethyl-Ndiisopropylammonium chloride (PSPTC) (1.0 g), ethyl 2-bromoacetate ( $1.0 \mathrm{~g}, 6 \mathrm{mmol}$ ) and $0.2 \mathrm{~g}$ biphenyl (internal standard in the analysis) in chlorobenzene solvent $(30 \mathrm{~mL})$ were added slowly to the mixture of well powdered sodium sulfide $(6 \mathrm{~g}, 77 \mathrm{mmol})$ in $10 \mathrm{~mL}$ water and agitated $(300 \mathrm{rpm})$ in a $250 \mathrm{~mL}$ three-necked Pyrex round - bottom batch reactor, which was immersed in a constant temperature $\left(60^{\circ} \mathrm{C}\right)$

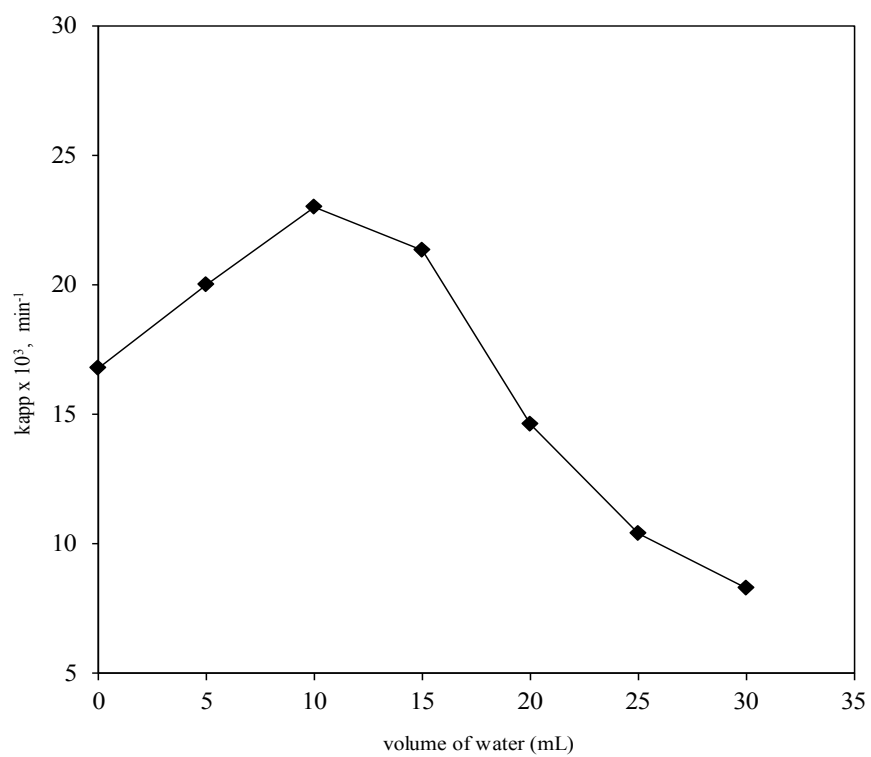

Figure 6: Effect of the amount of water on the synthesis of diethyl-2,2' thiodiacetate: $\mathrm{Na}_{2} \mathrm{~S}(9.25 \mathrm{mmol})$, ethylbromoacetate $(6.35 \mathrm{mmol}), 0.2 \mathrm{~g}$ biphenyl (internal standard), $60^{\circ} \mathrm{C}$, PSPTC $1 \mathrm{~g}$, chlorobenzene $30 \mathrm{~mL}, 300$ rpm, $40 \mathrm{kHz}, 300 \mathrm{~W}$. 


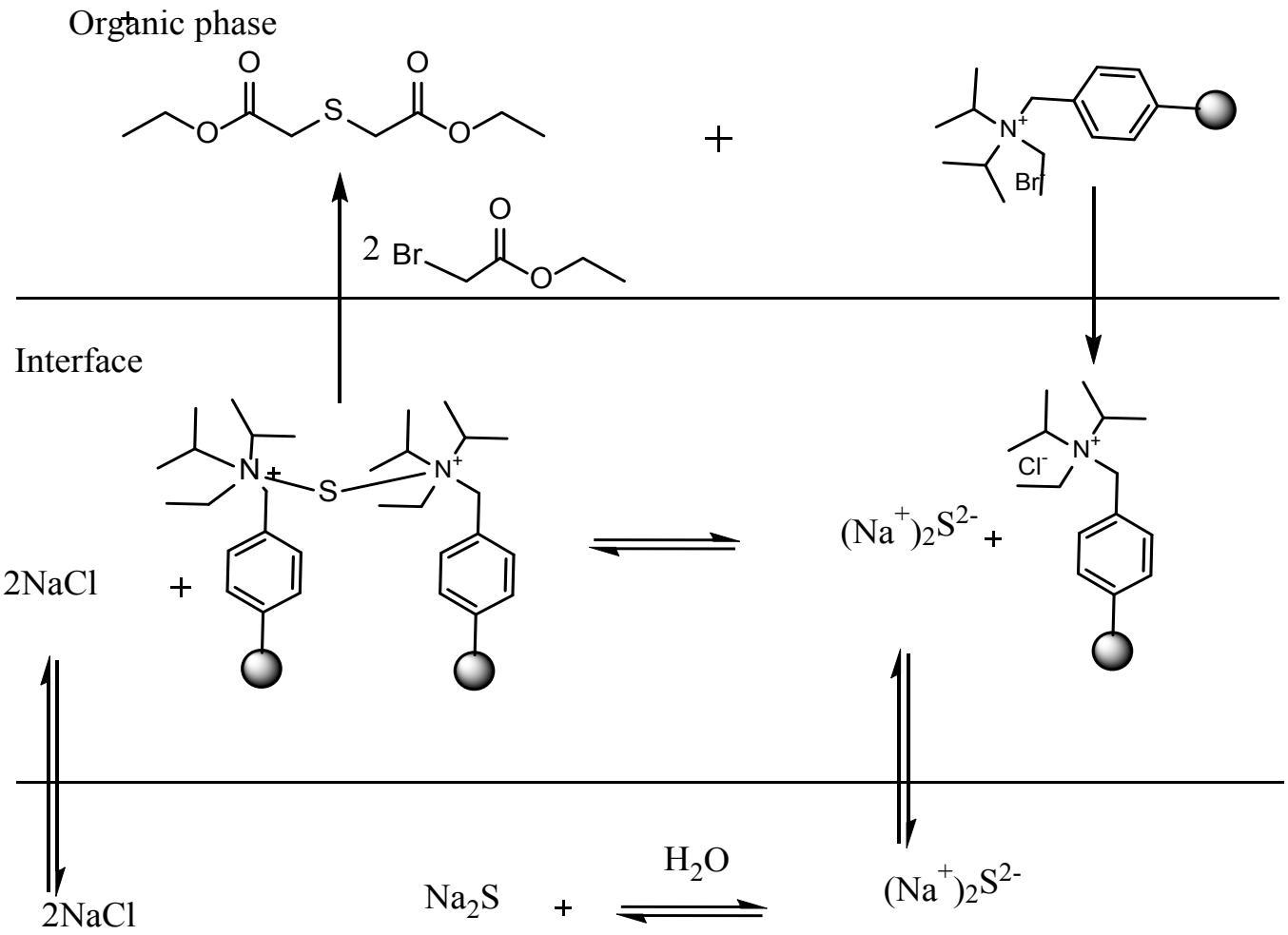

Aqueous phase

Scheme 5: Mechanism of the formation of diethyl-2,2'-thiodiacetate.

ultrasonicator $(40 \mathrm{kHz}, 300 \mathrm{~W})$. During the reaction, $0.2 \mathrm{~mL}$ of the organic sample was withdrawn at the chosen time and diluted into 3 $\mathrm{mL}$ of chlorobenzene. The samples analyzed by a gas chromatography (GC-Varian 3700 model). The product viz., (ethyl-2-bromoacetate) was determined from standard curve using biphenyl as an internal standard. In the present solid-liquid system, the mechanism (Scheme 5) is illustrated by the reaction of organic substrate (ethyl-2-bromoacetate, EBA) with the active intermediate $\mathrm{Q}_{2} \mathrm{~S}$. Without an extra addition of water, the polymer-supported mono-site phase transfer catalyst (QX) diffuses to the surface of the solid particles of $\mathrm{Na}_{2} \mathrm{~S}$ and converts it into the form of $\mathrm{Q}_{2} \mathrm{~S}$, which then dissolves in the bulk organic phase.

For the reaction of solid reactant $\mathrm{Q}_{2} \mathrm{~S}$ and organic substrate, ethyl2-bromoacetate (EBA) catalyzed by the polymer-supported mono-site phase transfer catalyst $(\mathrm{QX})$, the overall reaction is:

QX

$$
\mathrm{Na}_{2} \mathrm{~S}_{(\mathrm{s})}+\mathrm{EBA}_{\text {(org) }} \rightarrow\left(\mathrm{CH}_{3}-\mathrm{CH}_{2}-\mathrm{COOCH}_{2}\right)_{2} \mathrm{~S}_{(\text {org) }}+\mathrm{NaCl}_{(\mathrm{S})}
$$

Where (S) indicates the solid phase.

The following steps are contained in the overall reaction:

Reaction of $\mathrm{Na}_{2} \mathrm{~S}$ with $\mathrm{QX}$ produce of $\mathrm{Q}_{2} \mathrm{~S}$ at near the solid-liquid interface. This reaction is usually reversible and fast compared with the intrinsic organic reaction. This reaction is written as:

$$
\mathrm{Na}_{2} \mathrm{~S}+\mathrm{QX} \leftrightarrow \mathrm{Q}_{2} \mathrm{~S}_{\text {(org) }}+\mathrm{NaX}_{\text {(org) }}
$$

\section{Equilibration of KX}

The product KX (org) is also in equilibrium with its solid parts and is limited by the solubility in the organic phase:

$$
\mathrm{NaX}_{(\text {org) }} \leftrightarrow \mathrm{NaX}_{(\mathrm{s})}
$$

(i) Reaction of $\mathrm{Q}_{2} \mathrm{~S}$ with benzyl chloride, EBA to form the desired product viz., ethyl-2-bromoacetate, $\left(\mathrm{CH}_{3}-\mathrm{CH}_{2}-\mathrm{COOCH}_{2}\right)_{2} \mathrm{~S}$ which is represented in the equation (4).

$$
\mathrm{Q}_{2} \mathrm{~S}_{(\text {org) }}+\mathrm{EBA}_{(\text {org) }} \rightarrow\left(\mathrm{CH}_{3}-\mathrm{CH}_{2}-\mathrm{COOCH}_{2}\right)_{2} \mathrm{~S}_{(\text {org })}+\mathrm{QCl}_{(\mathrm{s})}
$$

\section{Conclusion}

In the present study, the rate of the reaction was controlled to study the kinetic aspects of the formation of the ethyl-2-bromoacetate from sodium sulfide and ethyl-2-bromoacetate (EBA) under ultrasonic-PSPTC condition. The apparent reaction rates were observed to obey the pseudofirst order kinetics, performing the reaction in ultrasonic condition resulted in shorter reaction time. The reaction mechanism and the apparent rate constants were obtained from the experimental results, the apparent rate constants are found to be directly dependent on each kinetic variables, viz., (PSPTC), ultrasonic frequency, stirring speed and temperature. However it decreases with increase in the volume of water and volume of chlorobenzene. Energy of activation was calculated from the Arrhenius plot. Based on the experimental evidence, an interfacial mechanism has been proposed. Combination of ultrasound and PSPTC resulted in better 
Citation: Rajendran V, Harikumar K (2015) Ultrasound Assisted Synthesis of Diethyl-2,2'-Thiodiacetate with 2-Bromoethylacetate Under a New Polymer-Supported Phase-Transfer Catalyst in Solid-Liquid Condition. Chem Sci J 6: 94. doi:10.4172/2150-3494.100094

efficacy as compared to the individual operations.

\section{Acknowledgment}

The authors would like to thank, The Pachaiyappa's Trust, Chennai, Tamil Nadu, India-600 030 and Sri Chandrashekarendra Saraswathi Viswa Mahavidyalaya, Deemed University, Enathur, Kanchipuram, Tamil Nadu, India 631561 , for their grant of permission to do this research work. The Author VR acknowledge also thanks The University Grants Commission for financial support for this research work.

\section{References}

1. Makosza M (2000) Phase-transfer catalysis.A general green methodology in organic synthesis. Pure App Chem 72: 1399-1403.

2. Mukherjee DK, Ghosh N (2008) Enantioselective phase transfer alkylation using orthopalladated complex in chiral ionic liquid. Cataly Commun 9: 40-44.

3. Devulapelli VG, Weng HS (2009) Synthesis of cinnamyl acetate by solid-liquid phase transfer catalysis: Kinetic study with a batch reactor Cataly Commun 10: 1638-1642.

4. Yadav GD, Bisht PM (2004) Novelties of microwave assisted liquid-liquid phase transfer catalysis in enhancement of rates and selectivities in alkylation of phenols under mild conditions, Catal Commun 5: 259-263.

5. Kaczmarczyk E, Janus E, Milchert E (2006) Epoxidation of 1,4-bis(allyloxy) butane by hydrogen peroxide using phase transfer catalysis. J Mol Cataly A: Chem 244: 173-178.

6. Sengupta S, Basu JK (2009) Kinetics of Benzyl Butyrate Synthesis under SolidLiquid Phase Transfer Catalysis. Inter Chemical Reactor Engineering 7: 1-18.

7. Mahdavi H, Amani J, Rahimdoost N (2008) Triphenylphosphine oxide on noncross-linked maleimide-styrene copolymer support: As a novel stable phase transfer catalyst Catal Commun 9: 2532-2535

8. Desikan S, Doraiswany LK (1995) The Diffusion-Reaction Problem in Triphase Catalysis. In Eng Chem Res 34: 3524-3537.

9. Regen SL (1975) Triphase catalysis. J Am Chem Soc 97: 5956-5957.

10. Wang ML, Wu HS (1992) lon-exchange rate limitation on a polymer-supported phase transfer catalytic reaction. J Polym Sci Part A: Polym Chem 30: 13931399.

11. Wang ML, Lee ZF, Wang FS (2005) Phase-Transfer-Catalyzed Etherification of 4,4'-Bis(chloromethyl)-1,1'-biphenyl with 1-Butanol by Polymer-Supported Catalysis, Ind Eng Chem Res 44: 5417-5426.

12. Montanari F, Quici S, Tundo P (1983) Mechanism of reactions promoted by polymer-supported phase-transfer catalysts. J Org Chem 48: 199-202.

13. Annunziata R, Benaglia M, Cinquini M, Cozzi F, Tocco G (2000) A Poly(ethylene glycol)-Supported Quaternary Ammonium Salt: An Efficient, Recoverable, and Recyclable Phase-Transfer Catalyst. Org Lett 2: 1737-1739.

14. Idoux JP, Wysocki R, Young S, Turcot J, Ohlman C, et al. (1983) PolymerSupported "Multi-Site" Phase Transfer Catalysts. Synth Commun 13: 139-144.

15. Ali HES (2007) Cycloalkylation reactions of fatty amines with $\alpha, \omega$-dihaloalkanes: Role of bis-quaternary ammonium salts as phase-transfer catalysts. Catal Commun 8: 855-860.

16. Kiasat AR, Mirzajani R, Shalbaf H, Tabatabaei T (2009) Nuclephilic ring opening of epoxides promoted by multi-site phase-transfer catalyst: An efficient and eco-friendly route to synthesis of $\beta$-hydroxy-thiocyanate. Chin Chem Lett 20: $1025-1029$.

17. Vivekanand PA, Balakrishnan T (2009) Superior catalytic efficiency of a new multi-site phase transfer catalyst in the C-alkylation of dimedone - A kinetic study. Catal Commun 10: 1371-1375.

18. Yang HM, Lin DW (2011) Third-liquid phase-transfer catalyzed esterification of sodium benzoate with novel dual-site phase-transfer catalyst under ultrasonic irradiation. Catal Commun 14: 101-110.

19. Jayachandran JP, Wang ML (2001) Selective dichlorocyclopropanation of dicyclopentadiene under controlled phase transfer catalysis conditions, Appl. Catal. A: Gen 206: 19-28.

20. Fedorynski M (2003) Syntheses of gem-Dihalocyclopropanes and Their Use in Organic Synthesis. Chem Rev 103: 1099-1132.
21. Janet EA, Susan B, O'Neill M, Smith A (1996) Merck Index (12thedn), Chapman \& Hall, New York, USA

22. Shaffer TD, Kramer MC (1990) Cyclization versus polymerization in phase transfer catalyzed polytioetherification, Makromol Chem 191: 71-76.

23. Shaffer TD, Kramer MC (1990) Bimechanistic phase transfer catalyzed polythioetherification. Makromol Chem 191: 3157-3162.

24. Yadav GD, Subramanian S (2004) Novelties of solid-liquid phase transfe catalyzed synthesis of o-nitrodiphenyl ether. J Mol Cat A: Chem 209: 75-82.

25. Sasson Y, Neumann R (1997) Handbook of Phase Transfer Catalysis, Chapman \& Hall, New York, USA

26. Starks CM, Liotta CL, Halpern M (1994) Phase Transfer Catalysis: Fundamental, Applications and Industrial Perspectives, Chapman \& Hall, London, Pp 321.

27. Yadav GD (2004) Insight into green phase - transfer catalysis. Top Catal 29 145-156.

28. Idoux JP, Wysocki R, Young S, Turcot S, OhIman C, et al. (1983) PolymerSupported "Multi-Site" Phase Transfer Catalysts. Synth Commun 13: 139-144.

29. Jayachandran JP, Wang ML (1999) A New Phase Transfer Reagent for the Addition of Dichlorocarbene to Olefins Under Mild PTC Conditions. Synth Commun 29: 4101- 4108.

30. Jin G, Ido T, Goto S (2003) Rate enhancement effect of third liquid phase on dibenzyl ether production in solid-liquid-liquid phase transfer catalytic system. Catal Today 79-80: 471-478.

31. Li X, Wang J, Mason R, Xiu R Bu, Harrison J (2002) Combined phase transfer catalysis and ultrasound to enhance tandem alkylation of azo dyes. Tetrahedron 58: 3747-3751.

32. Li X, Santos J, Bu XR (2001) Phase transfer catalysis and ultrasound in tandem alkylation of azo dyes for bifunctional molecules. Tetrahedron Lett 41: 40574062.

33. Yadav GD, Jadhav YB (2003) Novelties of Solid-Liquid Phase Transfer Catalysed Synthesis of $\alpha$-lsopropyl-p-chlorophenyl Acetonitrile from p-Chlorophenyl Acetonitrile. Org Proc Res Dev 7: 588-593.

34. Mason TJ (1997) Ultrasound in synthetic organic chemistry, Chem Soc Rev 26: 443- 451.

35. Li CJ (1993) Organic reactions in aqueous media - with a focus on carboncarbon bond formation. Chem Rev 93: 2023-2036.

36. Li CJ (1996) Aqueous Barbier-Grignard type Reaction: Scope, Mechanism, and Synthetic Applications. Tetrahedron 52: 5643-5649.

37. Loupy A, Petit A, Hamelin J, Texier-Boullet F, Jacquault $P$, et al. (1998) New Solvent-Free Organic Synthesis Using Focused Microwaves. Synthesis 9 1213-1238.

38. Varma RS, Naicket KP, Kumar D (1999) Can ultrasound substitute for phase-transfer catalyst? Triphase catalysis and sonochemical acceleration in nucleophilic substitution of alkyl halides and a-tosyloxyketones: synthesis of alkyl azides and $\alpha$-azidoketones. J Mol Catal A: Chem 149: 153-157.

39. Price GJ (1993) Current Trends in Sonochemistry, Royal Society of Chemistry, Cambridge. Pp. 183.

40. Luzzio FA, Moore WJ (1993) Ultrasound in oxochromium(VI)-mediated transformations. 2. Ultrasound-mediated preparation and applications of chromyl chloride. J Org Chem 58: 512-519.

41. Luche JL (1998) Synthetic Organic Sonochemistry. Plenum Press, New York and London, pp: 431.

42. Luche $J L$ (1997) A few questions on the sonochemistry of solutions. Ultrason Sonochem 4: 211-215.

43. Luche JL, Cintas P (1995) Active Metals, VCH Publishers, Wein-Heim pp: 133

44. Suslick KS, Docktycz D (1990) The effects of Ultrasound on solids in Advances in Sonochemistry, In: Mason TJ (eds.) JAI Press, New York, pp: 197-230.

45. Loupy A, Luche JL (1997) Sonochemical and microwave activation in phase transfer catalysis, In: Sasson Y, Neumann R (eds.) Springer Netherlands, London, pp: 369-404

46. Luche JL (1993) Advances in Sonochemistry, 3 In: T.J. Mason (eds.) JAI Press, London, pp: 85. 
Citation: Rajendran V, Harikumar K (2015) Ultrasound Assisted Synthesis of Diethyl-2,2'-Thiodiacetate with 2-Bromoethylacetate Under a New Polymer-Supported Phase-Transfer Catalyst in Solid-Liquid Condition. Chem Sci J 6: 94. doi:10.4172/2150-3494.100094

47. Yang HM, Peng GY (2010) Ultrasound-assisted third-liquid phase-transfer catalyzed esterification of sodium salicylate in a continuous two-phase-flow reactor. Ultrason Sonochem 17: 239-245.

48. Saïd K, Moussaoui Y, Kammoun M, Ben Salem R (2011) Ultrasonic activation of Heck type reactions in the presence of Aliquat-336. Ultrason Sonochem 18: 23-27.

49. Wang ML, Chen CJ (2010) Kinetic Study of Synthesizing 1-(3-Phenylpropyl) pyrrolidine-2,5-dione under Solid-Liquid Phase-Transfer Catalytic Conditions Assisted by Ultrasonic Irradiation, Org Process Res Dev 14: 737-745.

50. Yang HM, Li CC (2006) Kinetics for synthesizing benzyl salicylate by third-liquid phase-transfer catalysis. J Mol Catal A: Chem 246: 255-262.

51. Solati Z, Hashemi M, Ebrahimi L (2011) Rapid and Highly Selective Epoxidation of Styrene by meta -Chloroperbenzoic Acid Catalyzed by Manganese Meso -tetrakis(Pentafluorophenyl)Porphyrin in the Presence of Tetrabutylammonium Acetate and Bromide. Catal Lett 141: 163-167.

52. Kegnæs S, Mielby J, Mentzel UV, Jensen T, Fristrup P, et al. (2012) One-pot synthesis of amides by aerobic oxidative coupling of alcohols or aldehydes with amines using supported gold and base as catalysts. Chem Commun (Camb) 48: $2427-2429$.

53. Gorbanev YY, Kegnaes S, Riisager A (2011) Effect of Support in Heterogeneous Ruthenium Catalysts Used for the Selective Aerobic Oxidation of HMF in Water. Top Catal 54: 1318-1322.

54. Liu HH, Wang Y, Shu YJ, Zhou XG, Wu J, et al. (2006) Cyclopropanation of alkenes catalyzed by metallophthalocyanines, J. Mol Catal A: Chem 246: 49-52.

55. Wang ML, Hsieh YM, Chang RY (2003) Kinetic Study of Dichlorocyclopropanation of 1,7-Octadiene under Phase-Transfer Catalysis Conditions at High Alkaline Concentration. Ind Eng Chem Res 42: 4702-4707.

56. Wang ML, Rajendran V (2007) Ethoxylation of p-chloronitrobenzene using phase-transfer catalysts by ultrasound irradiation: a kinetic study. Ultrason Sonochem 14: 368-374.

57. Solati Z, Hashemi M, Ebrahimi L (2011) Rapid and Highly Selective Epoxidation of Styrene by meta -Chloroperbenzoic Acid Catalyzed by Manganese Meso -tetrakis(Pentafluorophenyl)Porphyrin in the Presence of Tetrabutylammonium Acetate and Bromide. Catal Lett 141: 163-169.

58. Azizian S, Kashimoto K, Matsuda T, Matsubara H, Takiue T, et al. (2007) Interfacial tension studies of crown ethers at air/water and hexane/water interfaces. J Colloid Interface Sci 316: 25-30.

59. Yang HM, Huang CC (2009) Green Conversion of Phenolic Compound to Benzoate Over Polymer-Supported Phase-Transfer Catalysts. Catal Lett 128: 235-242.

60. Wu HS, Wang CS (2003) Liquid-solid-liquid phase-transfer catalysis in sequential phosphazene reaction: kinetic investigation and reactor design. Chem Eng Sci 58: 3523-3529.

61. Weng Z, Wang J, Zhang S, Jian X (2008) Selective Oxidation of Benzyl Alcohol by Heteropolytungstate as Reaction-Controlled Phase-Transfer Catalyst with Hydrogen Peroxide. Bull Chem Soc Jpn 81: 525-529.
62. Rajendran V, Wang ML (2008) Dichlorocarbene addition to allyl phenyl ether under phase-transfer catalysis conditions- A kinetic study. J Mol Catal A: Chem 288: 23-27.

63. Baj S, Siewniak A, Socha B (2006) Synthesis of dialkyl peroxides in the presence of polymer-supported phase-transfer catalysts. Appl. Catal A: Gen 309: 85-91.

64. Desikan S, Doraiswamy LK (2000 Enhanced activity of polymer-supported phase transfer catalysts. Chem Eng Sci 55: 6119-6126.

65. Vivekanand PA, Balakrishnan T (2009) Superior catalytic efficiency of a new multi-site phase transfer catalyst in the C-alkylation of dimedone - A kinetic study, Catal Commun 10: 1371-1375.

66. Vivekanand PA, Balakrishnan T (2009) Catalytic Potential of a New PolymerAnchored Multisite Phase Transfer Catalyst in the Dichlorocarbene Addition to Indene. Catal Lett 13: 587-596.

67. Bhatkhande BS, Adhikari MV, Samant SD (2002) Sonochemical chlorooxidation of phenols using $\mathrm{HCl}-\mathrm{H} 2 \mathrm{O} 2$. Ultrason Sonochem 9: 31-35.

68. Margulis MA (2004) Sonochemistry as a new promising area of high energy chemistry. High Energ Chem 38: 135-142.

69. Mielby J, Kegnaes S (2013) Epoxidation of Alkenes with Aqueous Hydrogen Peroxide and Quaternary Ammonium Bicarbonate Catalysts. Catal Lett 143 1162-1165.

70. Ambulgekar GV, Bhanage BM, Samant SD (2005) Low temperature recyclable catalyst for Heck reactions using ultrasound. Tetrahedron Lett 46: 2483-2485.

71. Liu Y, Tsunoyama H, Akita T, Tsukuda T (2010) Efficient and selective epoxidation of styrene with TBHP catalyzed by $\mathrm{Au}(25)$ clusters on hydroxyapatite. Chem Commun (Camb) 46: 550-552.

72. Garcia-Bosch I, Company A, Fontrodona X, Ribas X, Costas M (2008) Efficient and selective peracetic Acid epoxidation catalyzed by a robust manganese catalyst. Org Lett 10: 2095-2098.

73. Nowrouzi N, Alizadeh SZ (2013) In situ generated acylimidazolium acetate as an efficient catalyst and acylating agent for the acetylation of alcohols, phenols, and amines at ambient temperature. Chinese J Catal 34: 1787-1790.

74. Kruus P, Burk RC, Entezari MH, Otson R (1997) Sonication of aqueous solutions of chlorobenzene. Ultrason Sonochem 4: 229-233.

75. Entezari MH, Heshmati A, Sarafraz-Yazdi A (2005) A combination of ultrasound and inorganic catalyst: removal of 2-chlorophenol from aqueous solution. Ultrason Sonochem 12: 137-141.

76. Abbott AP, Bell TJ, Handa S, Stoddart B (2005) O-Acetylation of cellulose and monosaccharides using a zinc based ionic liquid. Green Chem 7: 705-711.

77. Albanese D, Landini D, Maia A, Penso M (2001) Key Role of Water for Nucleophilic Substitutions in Phase-Transfer-Catalyzed Processes: A MiniReview. Ind Eng Chem Res 40: 2396-2402.

Submit your next manuscript and get advantages of OMICS Group submissions

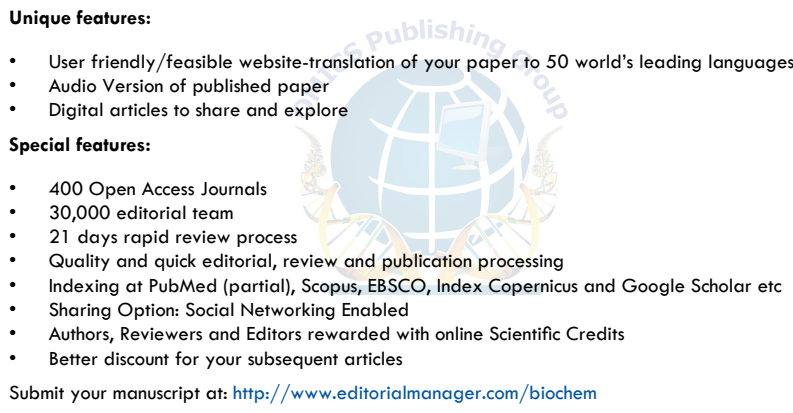

